UDK 792(497.4Ljubljana)»1892/1914«

Špela Lah

Filozofska fakulteta, Univerza v Ljubljani

Philosophical Faculty, University of Ljubljana

\title{
Slovensko-nemška dihotomija v Deželnem gledališču v Ljubljani med letoma 1892 in 1914
}

\section{Slovene-German Dichotomy in Provincial Theatre in Ljubljana between 1892 and 1914}

Prejeto: 7. oktober 2010

Sprejeto: 25. oktober 2010

Ključne besede: opera, Deželno gledališče v Ljubljani, leto 1892, slovenska direkcija, nemška direkcija

IZvLEČEK

Prispevek skuša osvetliti delovanje novega Deželenega gledališča v Ljubljani med leti 1892 in 1914, ko sta pod isto streho domovali slovenska in nemška gledališka direkcija. Avtorica približa bralcu temeljne značilnosti ene in druge (tehnično-organizacijske, repertoarne in izvajalske), ju skuša vzporediti, oziroma opozoriti na bistvene razlike med njima.

\author{
Received: 7th October 2010 \\ Accepted: 25th October 2010
}

Keywords: opera, Provincial Theatre in Ljubljana, year 1892, Slovene directorate, German directorate

ABSTRACT

The article tries to illuminate the effects of the newly new-constructed Provincial Theatre in Ljubljana between 1892 and 1914. This was the time, when the two directorates shared joint theatre premises: Slovene and German. The author draws attention to the main characteristics (technical, organizing, repertory and performing) of the two national managements and tries to compare them and to point out the principal distinctions between them.

Slovenska gledališka reprodukcija do danes še ni celostno obravnavana, saj zaenkrat ne obstaja študija, ki bi sistematično popisala in kritično ovrednotila dosežke slovenske dramske ter z vidika glasbene zgodovine in muzikologije pomembne operne umetnosti od njenih začetkov dalje. Tudi delovanje nemškega gledališča v zadnji četrtini 19. stoletja je zaenkrat še neobdelano polje glasbene zgodovine. ${ }^{1}$ Pričujoči prispevek seveda ni

Z delovanjem nemškega gledališča v Ljubljani sta se podrobneje ukvarjala Dušan Ludvik in Jože Sivec. Dušan Ludvik, Nemško gledališče v Ljubljani do leta 1790, disertacija na FF, Ljubljana 1957. Jože Sivec: Opera v Stanovskem gledališču v Ljubljani od leta 1790 do 1861, Ljubljana: Slovenska matica, 1971. Isti, Nemška opera v Ljubljani od leta 1861 do 1875, Muzikološki zbornik VIII (1972), str. 86-111. 
namenjen odpravi te praznine, ampak odpira nekatera vprašanja, ki bi zahtevala dve temeljiti, obsežni in samostojni raziskavi. ${ }^{2}$ Različni avtorji so se v krajših prispevkih sicer že ukvarjali s posameznimi segmenti delovanja slovenskega in nemškega gledališča, splošen pregled slovenske glasbene zgodovine pa v grobih orisih zabeleži (tudi) glavne značilnosti prvih samostojnih korakov slovenskega Deželenega gledališča. S tem so do določene meje že razkriti temelji prvih desetletij delovanja slovenske institucije oziroma poslednje obdobje nemške, poglobljeno védenje pa naj bi razkrilo tudi pogoje, značilnosti ter kvalitativni parameter ene in druge. Namen članka je soočiti dve nacionalni strani, poiskati skupne značilnosti, predvsem pa opozoriti na tiste bistvene razlike med njima, ki so najpomembneje in najbolj opazno zaznamovale glasbeno-gledališko produkcijo v Ljubljani.

Nemško gledališče je imelo do 90-ih let 19. stoletja že bogato tradicijo, vkoreninjeno v glasbeno življenje Ljubljane in zavest njenih prebivalcev. Nasprotno pa je prve resnejše gledališke poskuse Slovencem omogočilo leta 1867 osnovano Dramatično društvo, ki je predstave pripravljalo na čitalniškem odru. Že leta 1869 si je društvo izborilo prostor na odru nemškega Deželnega gledališča, vendar za le nekaj večerov mesečno. Ob tem so nemški gledališki podjetniki brez večjega nasprotovanja odstopili gledališke prostore $\mathrm{v}$ slovenske namene, kakor jim je narekoval četrti člen najemne pogodbe. ${ }^{3}$ Večina igralnih dni je bila še vedno nemških, lastniške lože so bile med slovenskimi večeri zaklenjene in prazne. Tako strpno sožitje je trajalo vse do izbruha požara februarja 1887, ki ni uničil le stavbe starega Deželnega gledališča, pač pa z leti tudi nemški primat znotraj tega.

Po požaru je v gledališki dejavnosti zavladala praznina, ki jo je zapolnila šele izgradnja novega gledališča. Otvoritev jeseni 1892 ni pomenila le pridobitev novega, modernega kulturnega doma, pač pa je nujno sprožila tudi nekatere tehnično-organizacijske spremembe. Te sicer niso pomembno vplivale na sam potek dela, kakršno je bilo pred tem značilno v okviru nemškega gledališča. Bistvena novost je bilo sobivanje slovenske in nemške direkcije pod skupno gledališko streho, kar je pomenilo delitev skupnih gledaliških prostorov, to je odra, zaodrja, avditorija, garderobe. Vodstvi pa sta še naprej razpolagali z lastnim fundusom, biblioteko, kostumi in tehnično opremo. Prav tako sta morali spoštovati s pogodbo določeno razporeditev uporabe odra $\mathrm{v}$ namen »skušenj«. Pomembno je vplivala tudi odločitev za odpravo pravice do lastninjenja lož, kar je pomenilo velik napredek predvsem za oba podjetnika, sprva nemškega in po letu 1869 tudi slovenskega, ki sta bila v starem gledališču prav zaradi posebnih pravic lastnikov lož marsikdaj ob zaslužek. Največjo spremembo pa je pomenila delitev igralnih dni: medtem ko so bili gledališki večeri do požara skoraj izključno nemški, se je zaradi slovenskih predstav v novi gledališki hiši število nemških zmanjšalo. ${ }^{4} \mathrm{~S}$ sezono 1909/10 so se neugodne razmere, ki so že dalj časa pestile nemško gledališko vodstvo, še poslabšale, saj je deželni odbor ugodil želji dramatičnega društva in mu odobril štiri

\footnotetext{
Repertoarni popis in kritično ovrednotenje delovanja nemškega Deželnega gledališča po letu 1875 je že v pripravi v okviru raziskovalnega procesa avtorice članka.

Arhiv Republike Slovenije. Deželni zbor in odbor, Pogodba z dne 27. 7. 1875, a.e. 5552, š. 333.

Prvo leto uprizarjanja na velikem gledališkem odru sta bili v slovenske namene dodeljeni dve predstavi tedensko. Že v sezoni 1894/95 so Slovenci pridobili še dan več, torej tri tedensko, kar je veljalo vse do leta 1909. AS 33, akti 7551 (1892), 2714 in 3536 (1894).
} 
igralne dni v tednu. ${ }^{5}$ Nemškemu gledališkemu podjetju so bili tako namenjeni le trije dnevi: ponedeljek, sreda in petek; odvzeti so mu bili vikendi in prazniki. ${ }^{6}$

Gledališko življenje, ki je potekalo po skupni, dvonacionalni tirnici, je bilo sprva enakopravno le na papirju. Slovenska vztrajnost in spremembe v vladni politiki, ki so vplivale tudi na sestavo deželnega zbora, pa so začele kazati rezultate tudi v gledališkem življenju tedanje Ljubljane. Namen Slovencev, ki ga je pravzaprav napovedala že otvoritvena predstava septembra 1892, je bil popoln prevzem kulturne institucije. Cilj je bil dosežen leta 1911, ko je s cesarjevo pomočjo ter s pomočjo kranjske hranilnice in prostovoljnih prispevkov ljubljanskih Nemcev nemško gledališko društvo zgradilo novo, nemško gledališko hišo. ${ }^{7}$ Ljubljana je s tem dobila dve, nacionalno in ogranizacijsko povsem ločeni gledališči.

Temeljni in hkrati najbolj zanesljiv vir pričujočega prispevka je rekonstrukcija repertoarne sheme, ki jo omogočajo v celoti ohranjeni dokumenti. Repertoarna politika nemškega vodstva se je pokazala za povsem primerljivo z drugimi provincialnimi gledališči avstrijskih dežel. Pri oblikovanju programa se je vodstvo usmerilo predvsem na splošen in prevladujoč okus ljubljanskega občinstva, ki je narekovalo slogovno in žanrsko zasnovo gledaliških prireditev. Kot drugod so tudi v Ljubljani prevladovale lahkotne zvrsti - veseloigre, burke, farse. Daleč najbolj priljubljena pa je bila opereta, fenomen evropske glasbene tvornosti, eden vodilnih žanrov množične kulture v industrijski epohi in kot najpomembnejša značilnost - bila je zvrst široke palete prebivalcev, od buržoazije do delavcev. Njena formalna odprtost, 'nezahteven' glasbeni jezik in težnja po aktualnosti so ji odprli pot iz Offenbachovega Pariza na Dunaj, v London in Berlin, pa tudi na vzhod.

Poleg te vedre, lahko umljive in pojmljive glasbene produkcije je imela opera posebno mesto. Pomenila je izjemen dogodek, ki je pritegnil, posebno, če je bilo javno znano, da je angažiran sposoben vodilni operni kader. Pa vendar, medtem ko so ljudje drli v gledališče, ko je bila na sporedu nova opereta, predstave pa so bile lahko tudi več večerov zapored povsem razprodane, je uprizoritev opernega dela sicer vzbudila zanimanje, ki pa je po reprizi ali dveh navadno povsem zamrlo. Podjetniki so, razumljivo, prisluhnili željam in zahtevam obiskovalcev, saj se je z razprodanimi večeri polnila tudi gledališka blagajna. Zavoljo tega so marsikdaj povsem opustili uprizarjanje finančno močno obremenilnih opernih del, saj so predstave pred napol prazno dvorano pomenile le deficit - umetniški užitek je bil z vidika direkcije postranski, manj pomemben dejavnik.

Iz vpogleda v repertoarno shemo enega in drugega gledališkega vodstva je razvidno, da so Nemci opero gojili priložnostno, v soodvisnosti od višine vsakoletne subvencije (ki ni bila stalna) in od finančne zmogljivosti posameznega podjetnika, s katerim je bil tesno povezan tudi angažiran pevski kader. Prave operne sezone sta v novem ljubljanskem Deželnem gledališču pripravila le podjetnika Adolf Oppenheim (1896/97) in Berthold

\footnotetext{
Prošnjo za večje število slovenskih igralnih dni je Dramatično društvo utemeljilo z naraščanjem števila prebivalstva slovenske narodnosti, saj je bilo Nemcev na prelomu stoletja na Kranjskem le 5\%. Pri tem je društvo navedlo dejstvo, da so bile slovenske predstave večinoma razprodane, nemške pa se odvijale pred prazno dvorano; da pa se mu prepusti vse proste dni v tednu, se je zdelo nadvse pravično, saj "večji del slovenskega naroda lahko pride v gledališče le ob sobotah, nedeljah in praznikih, [...]. Brez nedeljskih predstav naše gledališče ne more biti ljudsko in narodno ter se ne more dvigniti v finančnem smislu«. AS 33 , akt 1865 (1909).

Laibacher Zeitung (LZg) 1909 II, št. 223, str. 2002.

LZg 1911 II, št. 228, str. 2156.
} 
Wolf, ki je obudil gojitev opere v sezonah 1902/03, 1903/04, 1905/06, 1907/08 in 1908/09. Bogat operni repertoar je pripravil tudi zadnji nemški gledališki podjetnik v Ljubljani, Hermann Roché, vendar so bile uprizoritve teh popolnoma v rokah gostujočih pevcev iz Celovca. V ostalih gledaliških sezonah med leti 1892 in 1914 je bil angažiran operetni ansambel, v ospredju pa so bile postavitve operetnih del. Tu in tam so se operetni pevci soočili tudi z opernimi vlogami, vendar kvalitete teh uprizoritev pogosto niso bile na ustrezni umetniški ravni.

Nasprotno so se Slovenci zavzeli za sistematično gojitev opernih del, s katerimi so postopoma širili iz leta v leto pestrejši in bogatejši repertoar. Kontinuirano umetniško rast, ki so jo predvsem v prvem desetletju obstoja izpričale slovenske operne uprizoritve, so bile v prvi vrsti odraz ciljno usmerjenega vodstva, ki si je še pred otvoritvijo nove gledališke hiše zadalo jasno začrtano vizijo, da dobi Ljubljana slovensko operno hišo, katere umetniška raven bi bila primerljiva z drugimi sorodnimi institucijami. K prvim korakom so jo pospremili sposobni, izobraženi člani; za uspešen začetek sta bila še posebej zaslužna glasbenika Fran Gerbič in Josip Nolli.

Najpomembnejša razlika med slovenskim in nemškim vodstvom je bila torej ciljna naravnanost enega in drugega: medtem ko je bil glavni namen nemškega podjetnika pridobiti si naklonjenost občinstva, zadovoljiti njegove potrebe, ugoditi njegovim željam in ob koncu sezone beležiti dobiček, je imelo slovensko vodstvo pred očmi daljnoročni razvoj institucije, ki ni bila zgolj v službi obiskovalcev, temveč se je še posebno osredotočila na vzgojo podmladka in s tem na napredek v domači odrski tvornosti.

Tako zastavljene naloge so nujno vplivale na repertoarno, pa tudi na organizacijsko politiko. Zavoljo svojega glasbeno-vzgojnega poslanstva so želeli Slovenci že na samem začetku zatreti prevlado operete. Zato so se ji skoraj v celoti povsem odpovedali, da bi s tem preprečili poplitvenje okusa slovenskih obiskovalcev. To jim je v večji meri tudi uspevalo, vse do menjave vodstva in finančne krize na prelomu stoletja, ko so se bili prisiljeni vedno pogosteje zatekati k uprizarjanju operetnih uspešnic. Tudi slovensko občinstvo namreč ni bilo imuno na lahkotno, duhovito in sproščujoče dogajanje, ki ga je nudila opereta, katero so gotovo z zanimanjem spremljali še v starem Deželnem gledališču v okviru tedaj edinega, nemškega podjetnika. Kar jim ni nudila domača direkcija, so tudi tokrat dobili pri konkurenčnih Nemcih, kjer je ta zvrst večinoma močno prevladovala. To je bilo seveda v korist nemški direkciji, saj so bile dvorane še naprej polne tudi po zaslugi slovenskega prebivalstva. Pri tem velja poudariti, da je bilo v okviru slovenskega gledališča tudi kasneje operetnih predstav vendarle bistveno manj. Medtem ko so nemški podjetniki posegli po malodane vsakemu, še tako 'cenenemu' produktu, je slovenski ravnatelj uprizarjal večinoma izbrana dela, ki so v drugih avstrijskih gledališčih in s strani nemškega Deželnega gledališča že izpričala uspeh in vsaj v določeni meri zagotovila ustrezno raven kakovosti. Razen uspešnic vodilnih skladateljskih imen dunajske in francoske operete so seveda uvrstili na program tudi izvirna domača dela te zvrsti in operete drugih slovanskih avtorjev.

Zavoljo bogate operne podnudbe je zanimanje za slovenske glasbeno-scenske uprizoritve naraščalo, posebno v sezonah, ko je bilo nemško vodstvo primorano povsem opustiti gojitev tega gledališkega žanra. Ker sta bila v ospredju družbenokulturni dogodek in umetniški užitek, ne pa manifestacija nacionalnih teženj, smemo 
domnevati, da so bili tako na nemških kot na slovenskih večerih obiskovalci v veliki meri isti. Pester in privlačen program slovenske opere je tako pritegnil tudi številne, sicer nemškim gledališkim prireditvam zveste obiskovalce. Kljub temu pa je bila ena primarnih nalog slovenskega gledališča vzgoja lastnega občinstva, brez katerega bi bil vprašljiv in praktično nemogoč obstoj ustanove, ki je bila še v povojih. Prebivalci mesta Ljubljane so bili do uničujočega požara vajeni predstav nemškega gledališkega podjetja in verjetno so bili le redki tako močno pod vplivom narodnostnih teženj in prepričanj, da se ne bi odzvali tudi privlačnemu nemškemu programu. Ne glede na kvaliteto nemških prireditev je bilo gledališče vkoreninjeno v zavest določenega sloja prebivalstva in imelo status sociološko-kulturnega dogodka, večernega druženja in zabave. Da z dolgoletno tradicijo ni bilo moč prekiniti kar čez noč, pričajo številne slovenske kritike, ki obžalujejo in predvsem obsojajo slovenske obiskovalce na nemških večerih. Vrhunec nacionalnega pritiska na slovensko javnost pa je bilo gotovo poročilo ob začetku sezone 1908/09, ko se septembrski nemiri še niso povsem ohladili. Časopisna notica namreč oznanja, da se bodo vršili ukrepi, ki naj bi omejili, če že ne povsem izkoreninili, slovenski obisk nemških predstav: "Preskrbljeno je, da se bodo nadzorovali obiskovalci nemškega gledališča in sicer v surho, da se dožene, kateri Slovenci obiskujejo nemške predstave ${ }^{8}$.

Vodstvu slovenskega gledališča je k pridobivanju stalnega občinstva pripomoglo dvoje: na eni strani pester in raznolik repertoar, katerega so si prizadevali izenačiti z nemškim ter ga celo preseči; na drugi pa pozitivna kritika, ki je bila vedno dober manipulator javnega mnenja. Kot že rečeno, so se Slovenci v prvi vrsti odpovedali 'plehki' opereti, ki je zasvojila občinstvo malih in velikih evropskih gledaliških hiš, saj naj bi bila ta zvrst ustvarjena predvsem za "hipni užitek, katerega vtisk je tako plitek in neznaten, da ga izbrišemo s prvim požirkom piva, ki ga izpijemo po gledališki predstavi.... [Zato] vsa Čast ... intendanci, da je zametala opereto in si z veliko opero izobrazila in vzgojila mnogobrojno, verno in zvesto občinstvo «. ${ }^{9}$ Namesto tega so se zavzeli za sistematično gojitev operne umetnosti, kar je bilo sicer 'voda na mlin' nemškega direktorja, ki se je s provincialno repertoarno politiko posvečal predvsem opereti, s katero je bil zagotovljen tudi slovenski obisk (kljub naporom slovenske strani se slovenski ljubitelji zabave niso hoteli odpovedati priljubljenemu žanru). In obratno: ker je bila opera stalnica slovenskega repertoarja, je slovensko gledališče upravičeno med obiskovalci pričakovalo tudi ljubljanske Nemce, ki so bili zelo dobrodošli. ${ }^{10} \mathrm{~V}$ prid slovenski Operi je bila tudi skrb za pridobitev in prevoz prebivalstva iz daljne okolice Ljubljane in drugih slovenskih krajev, zlasti z Gorenjske, Štajerske in Dolenjske. Posebni železniški prevozi, ki so bili organizirani prav v namen obiska slovenskega Deželnega gledališča, so namreč zagotavljali številne polne dvorane repriznih prireditev, katerim je vodstvo prilagodilo tudi čas začetka. ${ }^{11}$ Vsekakor je bila ta plast obiskovalcev, na katere Nemci niso mogli staviti, povsem slovenska.

Slovenski narod (SN) 1908, št. 232.

SN 1898, št. 257.

Tako na primer poroča Slovenski narod, da je bilo na uprizoritvi Cavallerie rusticane zapaziti "zlasti tudi mnogo Ljubljanskih Nemcev«. SN 1893, št. 240.

11 Povzeto po kritikah iz Slovenskega naroda. 
Med prvimi glavnimi nalogami časopisne kritike ${ }^{12}$ je bila pridobitev vpliva na zavest bralca oziroma gledališkega obiskovalca ter hvaliti, s tem vzpodbujati in polniti gledališko dvorano. V tem oziru so bila objektivnejša poročila v Laibacher Zeitung, ${ }^{13} \mathrm{ki}$ so slovenskim predstavam sicer namenjala manj pozornosti kot nemškim, a bila vendarle bolj nepristranska od tistih v Slovenskem narodu. Recenzent je pomankljivosti slovenskih gledaliških uprizoritev največkrat opravičeval z dejstvi slabih finančnih in organizacijskih razmer, neustezne odrske opreme, nezadostnih rekvizitov ipd. Povsem enako lahko beremo v poročilih o nemških gledaliških predstavah, vendar s pomembno razliko: recenzent nemških dogodkov se je za omiljeno kritiko odločil zavestno na podlagi lastnih prepričanj, poročevalec s slovenskega odra pa je bil ali pod vplivom ambicioznega ravnateljstva ali podrejen njegovim zahtevam. To dokazuje javni dopis ${ }^{14}$, objavljen v Slovenskemu narodu, v katerem neznani poročevalec razkrije dejansko stanje slovenske kritike. Zanimivo in značilno je, da je postala po objavi tega članka bolj konstruktivna in verodostojna ter realnejša. Vse to seveda ne pomeni, da so bile slovenske operne uprizoritve slabe. Nasprotno, z več dobrimi solisti ji je uspelo pripraviti marsikatero solidno, celo dobro predstavo. O tem pričajo tudi polne dvorane - nasprotno od nemških opernih prireditev, ki so pritegnile le prvič, morda drugič - so bile slovenske reprize večkrat razprodane, včasih so bili v parterju polno zasedeni celo ob strani dodani stoli. Vsekakor so leta trdega dela, velike vneme in požrtvovalnosti obrodili sadove, ki se kažejo v izboljšanju uprizoritev, izpopolnjeni odrski opremi in vedno bolj bogati lastni knjižnici.

Tako nemška kot slovenska direkcija sta se nenehno soočali z velikimi ekonomskimi in organizacijskimi težavami. Uprizarjanje operne umetnosti ni bilo le velik finančni zalogaj, saj je poleg zanesljive in dobre materialne osnove zahtevalo tudi ustrezno usposobljen kader. Bistvenega pomena pri uresničevanju ambicij je bil stalen ansambel, ki

12 Na tem mestu se prispevek osredotoča na kritiko liberalno usmerjenega Slovenskega naroda in nemškega Laibacher Zeitung. Pri tem pusti odprto vprašanje primerjalne kritike (predvsem s časopisnimi poročili klerikalnega Slovenca), ki bo zanimiva pri morebitnih nadaljnih in bolj poglobljenih razmišljanih o zgodovini Slovenskega gledališča.

13 Dramtično društvo kot upravitelj slovenskega Deželnega gledališča, ki se je že od samega začetka pritoževalo nad poročili ljubljanskega nemškega dnevnika, si je naposled pri deželnem odboru izborilo, da se poročevalcu Laibacher Zeitung odvzame pravica do ocenjevanja slovenskih predstav. V njegovih objavah so namreč prepoznali politične intencije, »v prvi vrsti namen, škodovati slovenskemu gledališču na korist nemškemu. [...] Ker poročila uradnega lista razburjajo tako občinstvo kakor gledališko osobje, vprašamo, ali je opravičen uradni list [...] sistematično uničevati velevažni slovenski kulturni Zavod, in iz zasobne mržnje hujskati proti posameznim članom slovenskega gledališča . Poročil o slovenskih dogodkih v Laibacher Zeitung zato ni moč zaslediti med leti 1897 in 1908. Zanimivo je, da je kljub vsemu ocene slovenskih predstav v sezoni 1908/09 zopet prevzel taisti avtor, podpisan z inicialko -n-. SN 1897, št. 272.

14 Časopisni članek je tako kompleksen, da ga velja objaviti v celoti: „Pravo zlo je, da se skuša onemogočiti vsaka prava odkritosrčna kritika, češ, kar je našega ne smemo zmanjševati in trgati - in kar ni hvala, se smatra za oškodovanje. Zlasti vidimo to pri gledališki kritiki. Res, občudovanje zaslužijo možje, ki zatajujejo sami sebe v toliki meri, da pišejo dostikrat proti svojemu pravemu prepričanju. Kdor hoče is kritike spoznati, kako je kaka predstava uspela, mora znati med vrstami čitati. Preštudirati mora vsako besedo in jo skrbno pretehtati. Samo žurnalistični virtuozi znajo tako pisati. Če je o kakem igralcu rečeno, da je bil izvrsten, pomeni to, da je bil dober; če je rečeno, da je bil dober, potem pomeni to, da je komaj za silo rešil svojo nalogo; če je rečeno, da je zadoščal, potem lahko strup vzamemo na to, da je bil pod vsako kritiko. Nadaljni žurnalistični »trik«je to, da poročevalec časih prav interesantno in pregnantno popiše dobre strani kake predstave, slabe strani predstave in posameznih igralcev pa-zamolči. S takimi žurnalističnimi finesam si zavaruje poročevalec hrbet in doseže vendar svoj namen:predstava je pohvaljena. In gledališka predstava se mora pohvaliti, na vsak način, ker sicer bi se reklo, da je poročevalec dotično igro ubil. Sčasoma se tega seveda vsakdo naveliča in opusti poročanje o gledališču. Ali je pa res potrebno, da se tako poroča. Intendanca je pač tega mnenja. Morda je bilo nekoč to mnenje tudi resnično opravičeno, namreč v začetku slovenskega gledališča. Danes pa ni več tako. Danes je slovensko gledališče tako ukoreninjeno, vzgojilo si je tako številno in zvesto občinstvo, da poročevalec pač nima več samo naloge, z ugodnimi recenzijami vabiti ljudi v gledališče. SN 1904, št. 283. 
je pomembno vplival na ugoden razvoj: s stalnim pevskim kadrom so namreč reprize oper zahtevale manj vaj in bile s tem manjše finančno breme. Hkrati je bilo več časa za študij novih vlog, kar je omogočilo postopno širitev opernega repertoarja. Medtem ko se je nemško vodstvo iz sezone v sezono soočalo s problematiko novoangažiranih članov, je bilo stanje slovenskega opernega ansambla vendarle ugodnejše: nekateri vodilni člani slovenskega opernega ansambla (ki so bili večinoma tujci) so ostali v Ljubljani po več sezon, kar je direkciji med drugim omogočalo tudi stalno bogatitev opernega repertoarja.

Ocena kakovosti pevcev, obravnavana $z$ daljše časovne distance, je mogoča le na podlagi kritiških zapisov, katerih objektivnost pa je močno relativna. Na ljubljanski oder je namreč stopilo le malo takih umetnikov, ki bi z vidika sodobne glasbeno-zgodovinske stroke sodili med mednarodno priznane glasbene osebnosti in bi našli svoje mesto v obstoječi leksikalni literaturi. ${ }^{15}$ To pa ne pomeni, da so bili rezultati teh, danes nepoznanih, neuveljavljenih operistov in drugih sodelujočih glasbenikov svoj čas manj pomembni ali manj kakovostni. Nasprotno: po mnenju tedanjih kritikov so bile operne predstave marsikdaj dobre, tudi zelo dobre, nekatere naj bi celo presegle okvire provincialnega gledališča.

Na splošno so pevci izkazovali različno raven interpretacije. Med angažiranimi solisti nemškega in slovenskega opernega ansambla so bili pogosto pevci, ki so prišli v Ljubljano kot začetniki, brez potrebne odrske rutine in z neustrezno izobraženim glasom. Pogosto pa so dobili mesto $\mathrm{v}$ ansamblu že vpeljani in zreli, a povprečni pevci, ki pa se niso uspeli uveljaviti na večjih, pomembnejših odrskih deskah. Le redki so izpričali ustrezno glasbeno izobrazbo in višjo raven opernega petja. Nadaljnjo prepreko za večji razcvet opernih uprizoritev je pomenila stalna menjava opernega kadra, saj so pevci pogosto zapustili kranjsko prestolnico po koncu sezone, še preden so uspeli dokončno vzpostaviti ustrezen stik z drugimi solisti, orkestrom in nenazadnje z občinstvom.

Za kakovost uprizoritev niso bili odgovorni le pevci solisti, ki so bili največkrat v središču pozornosti laičnega občinstva. Kritika je posebno pozornost namenila tudi dirigentu, ki je imel svoj čas osrednjo vlogo pri pripravi glasbeno-scenskih del. Največkrat je bil odgovoren za celoten glasbeni del predstave, katere uspešnost je bila odvisna od njegove temeljitosti, vestnosti in glasbene inteligence. Dirigentove naloge so bile študij uprizorjenega dela, priprava orkestra, pevcev, korepeticije in drugo. Njegova vključenost v celovito pripravo glasbeno-scenskega dela je bila torej mnogo širše zasnovana, kot je praksa danes. Seveda je bila tudi tu stalnost angažmaja bistvenega pomena, saj je bil dirigent eden najpomembnejših, če ne kar najpomembnejši člen glasbenega ansambla. Tudi s tega vidika so bile organizacijske možnosti slovenskega vodstva ugodnejše, saj se je v dveh desetletjih zvrstilo le nekaj dirigenstkih imen, med katerimi je bil na primer Hilarij Benišek slovenskemu gledališču zvest skoraj petnajst let.

H kvaliteti nemških in slovenskih opernih večerov so veliko prispevali tudi gostujoči solisti, med katerimi je bilo kar nekaj velikih imen tedanje glasbeno-gledališke scene (omenimo le Georgino Januschowsky, Grete Forst, Amalio Materna, Julio Kopacsy-Karc-

Avtorica se pri tem opira na dostopno leksikalno literaturo: Karl-Josef Kutsch, Großes Sängerlexikon (2000); Wilhelm Kosch, Deutsches Theater-Lexikon: biographisches und bibliographisches Handbuch (1953,1960,1992); Rudolf Flotzinger, Oesterreichisches Musiklexikon (2002-2006); Gracian Černušák et al., Česko slovenský hudební slovník osob a institucí (1963-1965). 
zag, Gustava Landauerja, Emmericha Schreinerja, Františka Pacala in Bohumila Ptáka). S svojim znanjem in visoko umetniško ravnjo interpretacije so lahko neposredno vplivali na ostale soliste, ki so ob boku eminentne glasbene osebnosti pogosto od sebe dali najboljše možno in bistveno pripomogli k splošnemu ugodnemu vtisu prireditve. Hkrati so lahko sloveča imena dober pokazatelj, kakšen naj bi bil ugled ljubljanske gledališke hiše in hkrati dokaz o finančnih zmogljivostih direkcije.

Repertoarni prerez razkrije, da je bilo dvojno, konkurečno in med seboj povsem neodvisno vodstvo celo dobrodošlo. Programa ene in druge nacionalne strani namreč nista le sovpadala, pač pa sta se medsebojno tudi pomembno dopolnjevala. ${ }^{16} \mathrm{~S}$ tem se je bogatilo kulturno življenje mesta Ljubljane in širilo umetniško obzorje njegovega prebivalstva, saj je gledališče še vedno pomenilo osrednjo obliko družabnega življenja. Primerjalna analiza obeh repertoarjev pokaže, da je predvsem slovenska direkcija naredila pomemben korak naprej in uprizarjala ne le dela, ki so bila občinstvu znana že s strani nemškega deželnega gledališča in so preverjeno privlačila, pač pa je, kar je pomembneje, Ljubljano obogatila s predstavitvami nepoznanih, novih glasbeno-scenskih opusov. Taka politika s strani Slovencev je bila povsem razumljiva, saj je moralo Dramatično društvo konkurirati uveljavljeni instituciji z bogato in dolgoletno tradicijo, ki je imela svoj krog zvestih in nikakor ne nezahtevnih obiskovalcev, med katerimi so bili seveda tudi Slovenci. Če je torej želelo domače vodstvo pritegniti pozornost, je moralo ponuditi nekaj novega.

Tako nemško kot slovensko vodstvo je ostalo zvesto uprizarjanju glasbeno-scenskih del starejših italijanskih in francoskih opernih skladateljev, med katerimi zasledimo na sporedu največkrat dela Verdija, med obiskovalci pa je bil najbolj priljubljen njegov Trubadur kot največkrat izvajana opera v obravnavanem obdobju. Poleg Verdija so med italijanskimi skladatelji mesto na repertoarju dobili še Donizetti, čigar glasba je zaradi spreminjajočega se okusa tudi med občinstvom izgubljala svojo nekdanjo privlačnost, ter Rossini in Bellini, ki pa sta bila na sporedu bolj izjemoma. Izmed starejših francoskih snovalcev opere je bil še vedno najbolj uveljavljen Meyerbeer, čigar najuspešneja opera Hugenoti je dominirala tudi v ljubljanski gledališki hiši. Razen njega so Ljubljančani poslušali še dela Gounoda, Boieldieuja, Halevya, Adama in Auberja. Gounodev Faust je veljal za eno najbolj priljubljenih glasbeno-scenskih del v Ljubljani in je bil, poleg Verdijevega Trubadurja, najpogosteje izvajana opera do izbruha prve svetovne vojne.

Posebno pozornost velja v pričujočem prispevku nameniti tistim ljubljanskim opernim premieram, ki so bile zanimivejše tako za tedanje obiskovalce kot tudi za sodobne muzikologe in glasbene zgodovinarje. V okviru slovenskega in nemškega gledališča je bil repertoar Verdijevih oper do prve svetovne vojne pri obeh dopolnjen z Aido (1898 in 1905) in Otellom (1903 in 1914). Že iz teh podatkov lahko uvidimo, s kakšno taktiko so Slovenci konkurirali za naklonjenost občinstva in marsikdaj prehiteli nemške kolege. Ker sta se obe vodstvi soočali s finančnimi ovirami, se seveda postavlja vprašanje, kako je uspelo slovenski strani določene novosti predstaviti prej kot nemški. K temu sta gotovo pripomogli že omenjena ciljna naravnanost k sistematični gojitvi operne

16 Programska shema nemške direkcije je povzeta po napovednikih v Laibacher Zeitung, slovenske pa po monografski publikaciji Repertoar slovenskih gledališč 1867-1967. 
zvrsti in 'priviligiranost' stalnega opernega ansambla, ki so jo v določeni meri uživali Slovenci. Poleg tega je omembe vredna tudi opora, ki jo je slovenskim kolegom večkrat nudila hrvaška operna hiša v Zagrebu. Tako si je lahko direkcija domačega gledališča predvsem v prvem desetletju delovanja priložnostno sposojala dekoracijsko in drugo odrsko opremo, kostume in notno gradivo, kar je seveda bistveno razbremenilo boren proračun. ${ }^{17}$

Nasprotno je bilo nemško gledališče odvisno od zasebnega inventarja, ki ga je imel v lasti aktualni podjetnik, spet to pa je bilo odvisno od njegovega finančnega stanja. Številni nemški direktorji niti niso razpolagali z ustreznim fundusom, ki bi jim omogočal gojitev opere, niti niso bili za to usposobljeni. Na tem mestu velja poudariti, da sta bila deželni odbor in gledališko društvo, ki sta odločala o primernosti kandidatov za prevzem gledališča, dovolj stroga in izbirčna, a izbira - spričo ravni provincialnega gledališča - ni bila vedno bogata in včasih so se morali zadovoljiti tudi z manj ustreznim. Od tod tudi nihanja v repertoarni ponudbi, kvaliteti ter posledično zasedenosti avditorija, značilnega za nemško gledališko hišo, saj so nemški podjetniki prihajali v Ljubljano zgolj za sezono, dve, le izjemoma več. Vodstvo - »intendanca - slovenskega gledališča pa je bilo vsaj v prvem desetletju delovanja bolj ali manj stalno in je lahko postopoma dopolnjevalo zbirko lastnih gledaliških del.

Zato ni presenetljivo, da so bile marsikatere opere v novem ljubljanskem gledališču uprizorjene najprej v domačem jeziku. Slovensko Dramatično društvo je tak 'boj' za uveljavitev in nenazadnje za svoj obstanek napovedalo že v prvi sezoni pod novo streho, ko je februarja 1893 postavilo na oder Cavallerio rusticano, ki je bila zavoljo kratkosti in asketske opreme gotovo dostopnejša mladi slovenski instituciji. Leoncavallovi Glumači so bili na nemškem sporedu že naslednjo sezono, medtem ko so omenjeno Mascagnievo uspešnico uprizorili prvič šele proti koncu leta 1903.

Zavoljo konkurenčosti se je repertoar (nehote) širil in bogatil. S tem je vplival na umetniško razgledanost obiskovalcev in njihov okus, hkrati pa so se večale tudi njihove zahteve. Z italijanskim verizmom, ki ga je v Ljubljano 'pripeljala' Cavalleria, se je Ljubljančanom predstavil tudi Puccini. Njegove uspešnice so prevzele ljubitelje lepe umetnosti po vsem svetu in tudi na Slovenskem, najbolj pa sta prepričali La Boheme in Madame Butterfly. Prva je bila v Ljubljani prvič upizorjena v okviru nemškega gledališča v sezoni 1898/99 (slovenska premiera je bila novembra 1903), drugo pa so najprej predstavili Slovenci jeseni 1908, proti koncu iste sezone pa še Nemci. Razen teh je nemško vodstvo v sezoni 1913/14 uprizorilo Puccinijevo še danes manj cenjeno, 'zahodnjaško' Deklico $z$ zahoda, katere na slovenskem repertoarju do prve svetovne vojne ne zasledimo. Nasprotno se je v obravnavanem obdobju, in sicer januarja 1910, zgolj v slovenščini pela skladateljeva Tosca.

Medtem ko so Nemci z omenjenimi premierami izčrpali 'bero' italijanskih del, so Slovenci repertoar obogatili še z dvema sodobnima operama. Prva je bila prvenec italijanskega skladatelja Alberta Franchettija, ki je leta 1888 zaslovel z veliko opero Asrael, legendo v štirih dejanjih. Ljubljančani so jo spoznali marca 1903. Drugo so postavili

Iz časopisnih kritik je razvidno, da so si Slovenci sposodili potrebno opremo ter kostume vsaj za opere Afričanka, Norma in Carmen. Domnevati smemo, da pa je bilo podobnih primerov predvsem na začetku delovanje slovenske opere še več. SN 1895 , št. 242, SN 1896, št. 293, SN 1897, št. 257. 
na oder novembra 1911. Izbran je bil intermezzo v enem dejanju Susanina skrivnost, s katerim je leta 1909 Ermanno Wolf-Ferrari dokočno utrdil svoj mednarodni sloves.

Podobno stanje razkrije tudi vpogled v premierne uprizoritve francoskih opernih del, predstavljenih v Ljubljani po letu 1892. V sezoni 1906/07 je slovenska direkcija na repertoar dodala Bizetev prvenec Lovci biserov, opero, ki se je s tem pridružila skladateljevi Carmen, po premieri leta 1886 eni najbolj priljubljenih francoskih oper v Ljubljan. Težko pričakovana je bila tudi Offenbachova nedokočana operna uspešnica Hoffmannove pripovedke, ki je zaradi velike tragedije v dunajski Ringoper leta 1881 osvajala gledališke odre z večjo časovno zamudo. V Ljubljani se je prvič pela ob vstopu v leto 1901, in sicer v nemškem, dve leti kasneje pa še v slovenskem jeziku. Francoskim novostim sta se pridružili še Massenetevi mojstrovini Manon in Werther. Obe sta bili jeseni 1907 oziroma januarja 1909 v Ljubljani najprej predstavljeni v slovenskem jeziku, medtem ko so Nemci v začetku sezone 1913/14 uprizorili le Wertherja.

Tudi v francoski operni literaturi je slovensko gledališko vodstvo našlo priložnost, da pritegne širšo ljubljansko javnost. Premierno je namreč pripravilo še dve operni deli, katerih na programu ljubljanskega nemškega gledališča do konca njegovega obstoja ne zasledimo. Najuspešnejša opera francoskega skladatelja Ambroisa Thomasa Mignon je bila postavljena na oder januarja 1905, tri leta in pol kasneje pa še Samson in Dalila Camilla Saint-Saënsa.

Iz obdobja predwagnerjanske nemške opere so se na repertoarju nemškega gledališča v Ljubljani obdržale redke uspešnice, ki so se v večji meri ohranile do danes: najbolj privlačno med njimi je bilo Webrovo mojstrsko delo Čarostrelec, ki je vedno polnilo gledališko dvorano. Ugajali so tudi Lortzing, Flotow in Nicolai. Čeprav že izpete, niso bile njihove romantične opere niti v slovenskem jeziku nič manj uspešne. Slovensko deželno gledališče je bilo sicer v rokah protinemško usmerjenih liberalcev, ki pa s svojo temeljno idejo niso bili tako radikalni, da bi ne upoštevali do tedaj tudi med slovenskimi ljubitelji operne umetnosti poznane in uveljavljene nemške operne produkcije.

Drugače je bilo z opusi postwagnerjanskih skladateljev. Medtem ko se je v tem oziru repertoar nemških opernih del v okviru nemškega Deželnega gledališča občutno razširil, so bili Slovenci bolj selektivni. Med premierami nemških opernih del izstopata svoj čas veliki, v wagnerjanskem duhu napisani uspešnici Evangeljnik, s katero je zaslovel Wilhelm Kienzl, in pravljična opera Janko in Metka, prvenec Engelberta Humperdincka. Seveda so v nemško govorečem prostoru izjemno popularni deli uvrstili na svoj program tudi Slovenci, saj je moralo domače vodstvo, kot že rečeno, najprej prisluhniti željam obiskovalcev, šele nato pa se prepustiti aktualnim nacionalnim težnjam. Slovenski ljubitelji umetnosti v Ljubljani so bili namreč dobro seznanjeni tako z dogajanjem v evropskem in svetovnem kulturnem prostoru, kot tudi z delovanjem nemške gledališke institucije pri nas, katere občinstvo so v večji meri še vedno bili (kljub morebitnim nasprotnim nacionalnim prepričanjem). Obe novosti sta se še pred prvo svetovno vojno peli tudi v slovenskem jeziku, prva v začetku leta 1907, deset let po ljubljanski premieri, druga pa leta 1910, petnajst let za tem, ko so jo v Ljubljani prvič poslušali v nemškem jeziku. Svoj čas je veliko popularnost užival tudi skladatelj madžarskega rodu Karl Goldmark, čigar prvenec in hkrati najuspešnejša opera Sabska kraljica je našla pot le na slovenski oder, in sicer ob koncu sezone 1909/10. Nemško 
vodstvo pa je na program vključilo le skladateljevo manj znano, po Dickensovem romanu napisano opero Čriček na ognjišču, ki je hitro poniknila v pozabo. Kot zadnja med velikimi uspešnicami iz nemške operne literature je prišla v Ljubljano glasbena drama Nižava, napisana pod vplivom italijanskega verizma, prepletena z duhom nemškega severnjaštva in edina izmed dvajsetih opernih del Eugena d'Alberta, kateri je uspelo prodreti na mednarodni operni prostor in se obdržati do danes. Tudi ta se je v Ljubljani prvič pela v nemškem jeziku, a ji je takoj v naslednji sezoni, oktobra 1909, sledila še slovenska postavitev. Razen omenjenih so nemški repertoar obogatila tudi dela danes manj pomembnih nemških skladateljev, kot so bili Hummel, Hausmann in Marschner.

Poseben umetniški dogodek so pomenile uprizoritve Wagnerjevih glasbenih dram, ${ }^{18}$ ki so bile izziv tako za nemško kot slovensko vodstvo. Četudi naj bi dal veliki skladatelj jasno vedeti, naj se njegove glasbene drame raje ne uprizarjajo, kot pa, da se uprizarjajo nepopolne, so jim posvečali veliko pozornosti tudi na odrskih deskah provincialnih gledališč, kakršno je bilo ljubljansko. ${ }^{19}$ Wagnerjeve mojstrovine so veljale za svojevrsten statusni simbol, četudi so zahtevale ogromen izvajalski aparat in bile tehnično zahtevne za celoten kader, tako za instrumentaliste, pevce in zboriste, kot za režijo, scenografijo, dekoracijo in ostalo odrsko opremo, prinašale pa so tudi velike organizacijske, finančne in kadrovske težave velikim in malim gledališkim odrom. A vendarle so se ti in oni s temi težavami spopadali bolj ali manj uspešno. Prireditve Wagnerjevih opusov so bile pravi magnet za obiskovalce, ki pa so vedno in povsod potrebovali čas, da dozorijo za to, za svoj čas nenavadno in drugačno glasbo. Po ocenah kritike so ljubljanski ljubitelji operne umetnosti dozoreli šele ob vstopu v novo stoletje in prav tedaj se je reprodukcija Wagnerjeve umetnosti tudi na slovenskih tleh dejansko šele razmahnila. ${ }^{20}$

Iz nemških, pa tudi iz slovenskih gledaliških recenzij je razvidno, da je bilo svoj čas splošno veljavno mnenje, da uprizoritve Wagnerjevih glasbenih dram na provincialnem odru ne morejo biti popolne, saj so takšne lahko le na prvovrstnih odrih oziroma na odru bayreuthske hiše. S tem so pisci vnaprej opravičevali nepopolnost izvedbe in svojo, večinoma prizanesljivo oceno. V Ljubljani so se skupno pele štiri Wagnerjeve stvaritve (Tannhäuser, Lohengrin, Leteči Holandec in Valkira), kar je bilo povsem primerljivo na primer s celovškim, pa tudi z zagrebškim gledališčem (v obeh se je poleg omenjenih pela še skladateljeva prva prodornejša opera Rienzi). (Za primerjavo: v Gradcu so celo tetralogijo Nibelunški prstan uprizorili že v sezoni 1882/83 in bili skladateljevim mojstrovinam ves čas izredno naklonjeni).

V Ljubljani so Wagnerjevim glasbenim dramam veliko pozornost posvečali predvsem Slovenci. Najbolj priljubljeno med vsemi, Lohengrin, so Nemci pripravili v treh sezonah s skupno sedmimi, Slovenci pa kar v petih sezonah z devetnajstimi ponovitvami. Letečega Holandca so na nemški repertoar uvrstili v dveh, na slovenski pa v treh sezonah.

18 Z uprizoritvami Wagnerjevih del na ljubljanskem odru sta se podrobneje ukvarjala že Jože Sivec in Katarina Bedina. Jože Sivec, "Wagner na slovenski glasbeni sceni", Slovenska opera v evropskem okviru: ob njeni 200-letnici (Ljubljana: SAZU, 1982), str. 73-91; Katarina Bedina, "Slovenska percepcija Richarda Wagnerja, wagnerjanstva in wagnerizma do tridesteih let dvajsetega stoletja", Zbornik ob jubileju Jožeta Sivca, ur. Jurij Snoj et al (Ljubljana, 2000), str. 193-204.

LZg 1907 I, št. 27, str. 235-236.

$20 \quad$ LZg 1907 I, št. 44, str. 387-388. 
Tudi tu je bilo številčno razmerje predstav podobno: prvi so opero izvedli skupno petkrat, drugi pa štirinajstkrat. Valkire slovenska direkcija do leta 1914 ni uvrstila na repertoar, v izvirniku pa so jo Nemci predstavili šestkrat v dveh sezonah. Nasprotno je bilo s Tannhäuserjem: nemški gledališki podjetniki ga pod novo gledališko streho niso več uprizorili (opera je bila v okviru nemškega Deželnega gledališča predstavljena le v sezoni 1873/74), v slovenskem jeziku pa so jo izvajali v treh sezonah, in sicer skupno trinajstkrat.

Poleg Wagnerja je v Ljubljani pozornost kritike in občinstva vedno vzbudil tudi Mozart. Njegove uspešnice, ki so še danes del železnega opernega reprtoarja, v obravnavanem obdobju seveda niso bile več novost. Pa vendar je Mozartova glasba zadonela v prostoru ljubljanskega gledališča tako zelo poredko, da je vedno pritegnila kot noviteta. Zanimivo je, da so se Mozartove opere do prve vojne na ljubljanskem odru Deželnega gledališča pele le v nemškem jeziku, saj se Slovenci vse do leta 1926 niso soočili s tehničnimi zahtevami, ki so bile pevcem provincialnih gledališč največkrat povsem tuje. Tudi nemškim interpretom je bila Mozartova glasba slogovno močno oddaljena in je zahtevala od njih veliko truda in vneme, da bi se njihovo podajanje vsaj približalo skladateljevemu duhu. V novi gledališki stavbi sta se do prve svetovne vojne peli le Figarova svatba (z dvema postavitvama v sezoni 1906/07) in le enkrat Don Giovanni dve sezoni kasneje. Posebno mesto med nemškimi opernimi skladatelji ima še danes Beethoven s svojo edino opero Fidelio, ki je bila v več kot sto letih, od nastanka leta 1805 pa do leta 1914, v okviru nemškega deželnega gledališča uprizorjena le trikrat (!), in sicer v sezonah 1873/74, 1896/97 in 1903/04, slovensko vodstvo pa jo je uvrstilo na repertoar šele leta 1927.

Z opernimi deli italijanskih, francoskih in nemških skladateljev so Nemci izpolnili svoj repertoar. Njihova repertoarna politika se je izkazala kot povsem primerljiva z drugimi provincialnimi gledališči avstrijskih dežel. Primerjalna analiza z Gradcem zgovorno prikaže dejansko stanje tedanje ljubljanske kulture, ki se je, kljub številnim, predvsem finančno pogojenim težavam, zadovoljivo približalo štajerski prestolnici. Že res, da je bila operna dejavnost v Gradcu neprimerno bogatejša in se je še posebno razmahnila ob otvoritvi nove operne hiše na prelomu stoletja. A vpogled v tamkajšne sezonske sporede razkrije skladateljska imena, katerih pomembnejše umetnine so spoznali tudi obiskovalci ljubljanske Talije. Šele v prvem desetletju novega stoletja je s Straussovima Salomo in Elektro graški repertoar doživel večji slogovni odmik od ustaljene prakse, katere Ljubljana do izbruha prve svetovne vojne ni presegla. ${ }^{21}$

Repertoarno shemo so Slovenci v okviru nacionalnega programa znatno razširili in svojo pozornost usmerili tudi v uprizarjanje oper bolj ali manj uveljavljenih slovenskih in slovanskih avtorjev. V želji, da bi k produkciji izvirnih del vzpodbudili domače avtorje, so vključevali dela hrvaških, čeških in poljskih skladateljev, ki si v svetovnem glasbenem merilu sicer niso pridobila vidnejšega mesta, za slovensko glasbeno-scensko ustvarjanje pa so pomenila zgledne primere, vzore tudi za slovenske skladatelje. Razen teh je slovensko vodstvo na domačem občinstvu uspešno preizkusilo tudi privlačno moč velikih skladateljskih imen z vzhoda in postavilo na oder odmevna dela kot so Čajkovskega

${ }^{21}$ Pri primerjalni analizi z graškim gledališkim repertoarjem se avtorica opira na pregledano arhivsko gradivo v graškem Opernem arhivu. 
Evgenij Onjegin in Pikova dama; Glinkova Ruslan in Ljudmila; Dvořakova Rusalka ter Smetanove Prodana nevesta, Dalibor in Poljub.

Nasprotno pa nemško vodstvo na svoj repertoar ni uvrstilo niti enega opusa vzhodnoevropskih skladateljev - niti Smetanove Prodane neveste ne, čeprav so jo, na primer, uspešno uprizarjali tudi v Celovcu in v Grazu. Razloga za to prav gotovo ne gre iskati v nacionalnih, protislovanskih težnjah. Gledališki podjetnik je bil v službi občinstva, ki je vplivalo na njegovo finančno stanje. Nacionalno in politično prepričanje je moralo biti in je bilo s tega vidika povsem nepomembno. Bolj verjetno je, da so imeli aktualni direktorji v Ljubljani v lasti predvsem tista dela, ki so preverjeno pritegnila pozornost na večjih in na manjših avstrijskih odrih ter so lahko obetala uspeh in dobiček. Tudi v tem oziru je bilo ljubljansko nemško Deželno gledališče v svoji programski politiki primerljivo z graškim. Slednje se je prav tako omejilo na dela zahodnoevropskih opernih skladateljev, vendar le z redkimi izjemami (poleg omenjene Smetanove uspešnice lahko zasledimo še njegovega Daliborja in Pikovo damo Čajkovskega). S tega vidika je bila konkurenčnost nacionalno nasprotnih si vodstev v Ljubljani prav tako dobrodošla, saj se je gledališki repertoar mesta Ljubljane zavoljo slovenske strani močno razširil, z vključitvijo slovanskih opernih del pa je postala gledališka dejavnost kranjske prestolnice stičišče vzhodne (kakršno je poznal na primer Zagreb) in zahodne prakse (primerljive na primer s koroško prestolnico Celovcem).

Jeseni 1911 je z otvoritvijo novega Jubilejnega gledališča cesarja Franca Jožefa nemško gledališko društvo uresničilo svoje dolgoletne ambicije, da se izvije iz primeža slovenskega gledališkega pola, ki ga je vse bolj omejeval pri njegovem delovanju in ga postopoma izrinjal iz prvotne gledališke hiše. Z otvoritvijo novega kulturnega doma so bili Nemci po dveh desetletjih zopet samostojni in - vsaj prostorsko in organizacijsko - neodvisni, Slovencem pa se je prav tako izpolnila dolgoletna goreča želja. A tudi nov kulturni tempelj niti enim niti drugim ni zagotavljal eksistence. Medtem ko se je slovenska, liberalno usmerjena direkcija soočala z velikimi notranje-političnimi pritiski in z nenaklonjeno klerikalno večino v deželnem odboru, so se Nemci izgubljali v vedno bolj slovenski Ljubljani, premajhni za dve gledališki instituciji. To potrjuje tudi nova vodstvena praksa, saj sta oba nemška gledališka direktorja v novi stavbi, Karl Richter in Hermann Roché, primarno delovala kot ravnatelja celovškega Mestnega gledališča, ljubljansko pa jima je bilo sekundarna dejavnost.

Kot je razvidno iz kratkega vpogleda v prva leta glasbeno-gledališke poustvarjalnosti v okviru nove kulturne institucije, se je dejavnost slovenskega Deželnega gledališča bistveno razlikovala od nemškega. Cilji, ki si jih je zastavila slovenska direkcija, so bili povsem drugačni od ciljev nemškega podjetnika. Gledališki dejavnosti, čeprav pod skupno streho in s podobnimi problemi, sta bili dva povsem različna svetova. Poznavanje enega je zato nujno za razumevanje drugega - in obratno. Četudi je v zavesti vkoreninjeno splošno veljavno mnenje, da so bili Nemci tisti, ki so ovirali slovensko kulturo na poti k njenim ciljem, nova spoznanja kažejo, da je bil obstoj nemškega gledališča z rojstvom slovenskega obsojen na propad, ki se je zdel neizbežen ne glede na izbruh prve svetovne vojne. 


\section{SuMMARY}

The opening of the Provincial Theatre in 1892 brought a new era to the stage performing arts in Ljubljana. It marked a new beginning of Slovene cultural life, and as regards German theatre production, up to that time firmly rooted in the conscience the Ljubljana burghers, an unexpected end. Up to 1887 , the year of the devastating fire, German theatre performances had had complete monopoly in the capital of Carniola; from then on, with this new cultural institution, they were joined by their Slovene counterparts. The Slovene directorship set ambitious goals that were, conditions permitting, conscientiously and ever more successfully realized.

The question of the binational character of the theatre administration has been so far documented only in fragments, and for the most part separately, in keeping with the two nationalities. The article therefore tries to achieve a systematic insight into the organisational, repertorial and performing characteristics of both sides, while drawing attention to the differences between them. These lay not so much in the management itself, since both directorships, the Slovene and the German, were being confronted with similar financial, spatial as well as cultural-political problems. Above all, they affected questions of programming: while the German side cultivated operatic art only occasionally, Slovenes decided on systematically programmed performances in this genre, which also included works by Slovene and Slavic composers, not to be found on German programmes. A comparison between their repertoires reveals that the two programme schemes did not coincide. On the contrary, they actually supplemented each other. Which enriched the social and cultural life of Ljubljana, broadening the artistic horizons of its inhabitants, all the more since the theatre was still the central scene of social life. 